\title{
Characterization of Occupational Exposure To Fungal Burden in Portuguese Bakeries
}

\author{
Carla Viegas ${ }^{1,2} \mathbb{D}^{\mathbb{D}}$, Tiago Faria ${ }^{3}$, Liliana Aranha Caetano ${ }^{1,4}{ }^{\mathbb{D}}$, Elisabete Carolino ${ }^{1}$, \\ Anita Quintal-Gomes ${ }^{1,5}$, Magdalena Twarużek ${ }^{6}$ (D), Robert Kosicki ${ }^{6}$ (D) and Susana Viegas ${ }^{2,1}$ \\ 1 Instituto Politécnico de Lisboa, H\&TRC—Health \& Technology Research Center, ESTeSL_Escola Superior \\ de Tecnologia da Saúde, 1990-096 Lisboa, Portugal \\ 2 Centro de Investigação em Saúde Pública, Escola Nacional de Saúde Pública, Universidade NOVA de Lisboa, \\ 1600-560 Lisboa, Portugal \\ 3 Centro de Ciências e Tecnologias Nucleares, Instituto Superior Técnico, Universidade de Lisboa, \\ E.N. 10 ao km 139,7, 2695-066 Bobadela LRS, Portugal \\ 4 Research Institute for Medicines (iMed.ULisboa), Faculty of Pharmacy, University of Lisbon, \\ 1649-003 Lisbon, Portugal \\ 5 Faculty of Medicine, Institute of Molecular Medicine, University of Lisbon, 1649-028 Lisbon, Portugal \\ 6 Faculty of Natural Sciences, Department of Physiology and Toxicology, Institute of Experimental \\ BiologyKazimierz Wielki University, Chodkiewicza 30, 85-064 Bydgoszcz, Poland \\ * Correspondence: carla.viegas@estesl.ipl.pt
}

Received: 21 June 2019; Accepted: 1 August 2019; Published: 2 August 2019

\begin{abstract}
Several studies reported adverse respiratory health effects in workers exposed to ambient contaminants in bakeries. The aim of this study was to examine worker exposure to fungi and mycotoxins in Portuguese bakeries in order to develop new policies in occupational health. Environmental samples such as air, surfaces, settled dust and electrostatic dust collector (EDC) were collected in 13 bakeries for fungal and mycotoxins assessment. Air samples obtained by impaction were performed applying malt extract agar (MEA) supplemented with chloramphenicol (0.05\%) and dichloran glycerol (DG18) agar-based media. Air samples collected through impinger method were determined as well for fungal detection by molecular tools of Aspergillus sections and mycotoxins. The highest median value for fungal load was $1053 \mathrm{CFU} \cdot \mathrm{m}^{-3}$ and $65.3 \%$ (32 out of 49 ) of the sampling sites displayed higher fungal load than limits imposed by the World Health Organization. Aspergillus genera was found in air, surface swabs and EDC. Molecular tools were effective in measuring Aspergillus section Fumigati in $22.4 \%$ on air, $27.8 \%$ on surface swabs and in $7.4 \%$ in EDC and Aspergillus section Versicolores in one air sample. All settled dust samples showed contamination with six to eight mycotoxins in each sample. The mycotoxins detected were deoxynivalenol-3-glucoside, deoxynivalenol, zearalenone, 15-acetyldeoxynivalenol, monoacetoxyscirpenol, diacetoxyscirpenol, fumonisin B1, fumonisin B2, griseofulvin, HT2, ochratoxin A, ochratoxin B and mycophenolic acid. Industrial hygienists and exposure assessors should rely on different sampling methods (active and passive) and different assays (culture based and molecular methods) to obtain an accurate risk characterization regarding fungal burden (fungi and mycotoxins). Additionally, the awareness for the raw material as a potential mycotoxins indoor contamination source is important.
\end{abstract}

Keywords: bakeries; fungal contamination; mycotoxins contamination; occupational exposure; multi-approach analyses

\section{Introduction}

Baking is a major industrial activity in Portugal and directly relates to the fact that Portuguese bread is a well-known product that is appreciated both nationally and internationally [1]. However, 
without precise numbers, this implies a considerable work force involving many workers in this specific occupational environment in Portugal.

In this setting 'baker's asthma' is one of the most common work-related respiratory diseases. Wheat sensitization prevalence rates of up to $30 \%$ have been reported for bakers [2]. The environment of bakeries is very complex, and has several potential sensitizers among cereal flours such as wheat, rye or barley. However, there are reports of baker's asthma caused by fungi, yeast, eggs, sesame seeds, nuts, and insects as well. The occurrence of sensitization to these allergens is less well known than those cases caused by cereal flours or enzymes, but they should be kept in mind in the clinical setting if no sensitization to common bakery allergens is found [3].

Several occupational exposure limits to flour dust were proposed as follows: (1) threshold limit value of $0.5 \mathrm{mg} / \mathrm{m}^{3}$ for flour dust in flour mills [4] by the American Conference of Governmental Industrial Hygienists (ACGIH); (2) $10 \mathrm{mg} / \mathrm{m}^{3}$ total dust and $5 \mathrm{mg} / \mathrm{m}^{3}$ for respirable dust in certain Canadian provinces [5]; (3) 4 and $3 \mathrm{mg} / \mathrm{m}^{3}$ for flour dust in Germany and Denmark, respectively; (4) $5 \mathrm{mg} / \mathrm{m}^{3}$ for organic dust in Finland, Iceland, and Norway [6]; and (5) $8 \mathrm{~h}$ TWA maximum exposure limit of $10 \mathrm{mg} / \mathrm{m}^{3}$ for flour dust, with a $15 \mathrm{~min}$ exposure limit of $30 \mathrm{mg} / \mathrm{m}^{3}$ by the health and safety commission of the United Kingdom [7]. Thus, differences exist in the exposure limits even within the same continent.

Considering the exposure limits, it is possible to recognize that the quantitative characterization of flour dust and allergens is based upon air or settled dust sampling [8]. However, flour is a complex organic dust encompassing one or a mixture of different cereal grains including wheat, rye, millet, barley, oats or corn cereal that have been processed or grounded by milling [9]. In addition, flour may contain several contaminants, such as fungi and mycotoxins [5,8], being the raw materials (such as different cereals and flour) entering the facilities the principal contamination sources for this occupational environment-as is the case in other settings where fungal burden was assessed [10].

Centered on the toxigenicity of several mycotoxins, regulatory levels have been established to food commodities by many national governments and adopted for use in national and international food trade. Internationally, Codex, the European Union (EU), and other regional organizations issued a number of decrees recommending maximal levels of mycotoxins in foods and feeds, which were used as guidelines for controlling contamination by mycotoxins for consumer safety [11]. In France, measurements in different food commodities—such as cereals, vegetables, and spices—showed no contamination above regulatory limits. However, workers' exposure via inhalation was high for all settings as the air measurements revealed significant levels of mycotoxins bound to dust particles [12]. Previously, Viegas et al. [13-16] demonstrated that occupational exposure to mycotoxins occurs essentially by inhalation. Recently, Viegas et al. [17] demonstrated that inhalation of mycotoxins on the workplace significantly adds to the exposure resulting from ingestion of mycotoxin-contaminated food.

The highest levels of exposure to organic dust occur in two different phases (mixing and baking) in both small and large bakeries and upon receiving and opening of flour containers in larger bakeries [18]. Several studies reported adverse respiratory health effects in workers exposed both in small and large-scale industries $[8,19,20]$. Indeed, adverse respiratory system symptoms and diseases were found to be induced by occupational dust being influenced by the type of dust, dose, duration of exposure and genetic factors.

Different sampling methods should be applied to ensure a more detailed occupational exposure assessment to fungal burden as each method has unique advantages and disadvantages. Thus, a multi-approach in the sampling methods will enrich data findings, therefore enabling a more accurate risk characterization $[10,21,22]$.

Until now, data covering a wider spectrum of the fungal burden (fungi characterization and mycotoxins presence), obtained by a multi-approach on sampling methods and assays in bakeries have not been reported, and this omission has barred the implementation of suitable preventive measures. This is of particular importance as "baker's asthma" can be caused by fungi as well. 
The aim of this study was to assess workers exposure to fungi and mycotoxins in Portuguese bakeries in order to develop new policies in occupational health.

\section{Materials and Methods}

\subsection{Bakeries Characteristics and Samples collection}

The study was conducted between November 2016 and June 2017 in 13 Portuguese bakeries located in the Lisbon district. The bakery samples were obtained through random selection of the bakeries covered in this study, which belong to two different companies that accepted to participate. Eight bakeries belonged to a large company producing bread for sale in their own stores as well as for different school canteens and vending machines. The other five bakeries were integrated into supermarket facilities and belonged to a supermarket representative of a large group of 292 units widespread in Portugal with similar features concerning the bakery section (Table 1).

Table 1. Environmental and raw material samples distributed for each bakery assessed for mycobiota analyses.

\begin{tabular}{ccccccc}
\hline & & \multicolumn{4}{c}{ Sampling Approaches (Samples Number) } \\
\cline { 3 - 7 } Bakery & Facilities & $\begin{array}{c}\text { Indoor Air } \\
\text { Sampling Impaction } \\
\text { MEA and DG18 }\end{array}$ & $\begin{array}{c}\text { Indoors Air } \\
\text { Sampling Impinger }\end{array}$ & $\begin{array}{c}\text { Surface } \\
\text { Swabs }\end{array}$ & $\begin{array}{c}\text { Settled } \\
\text { Dust \# }\end{array}$ & EDC * \\
\hline 1 & Enlarged company & 3 & 3 & 3 & - & 2 \\
2 & Enlarged company & 5 & 5 & 5 & - & 3 \\
3 & Enlarged company & 4 & 4 & 4 & 1 & 2 \\
4 & Enlarged company & 4 & 4 & 4 & 1 & 2 \\
5 & Enlarged company & 5 & 5 & 5 & 1 & 3 \\
6 & Enlarged company & $4+$ & 4 & 4 & 1 & 3 \\
7 & Enlarged company & 5 & 5 & 5 & 1 & 3 \\
8 & Enlarged company & 4 & 4 & 4 & 1 & 3 \\
9 & Supermarket & 4 & 4 & 4 & 1 & 3 \\
10 & Supermarket & 4 & 4 & 4 & 1 & 3 \\
11 & Supermarket & 4 & 4 & 3 & 1 & 3 \\
12 & Supermarket & 3 & 53 & 58 & 1 & 3 \\
13 & Supermarket & 4 & 53 & 4 & 5 & 36 \\
\hline
\end{tabular}

* Adopted from Viegas et al. [23]; \# Adopted [24] + Samples impacted on MEA were not possible to perform.

Most of the units were divided into three different areas which consisted of the sampling sites considered for this study: production - where kneading machines and ovens were located and where dough shaping was performed; raw material warehouse-where workers need to go several times to collect raw materials for dough preparation; store-where the final product is sold (bread or pastry). These areas correspond with the workplaces where the workers spend more time as well. In one of the bakeries without store a distinct area was assessed: expedition-where distribution of final product for other units occurs. Further, one bakery was only devoted to pastry. It is important to mention that normally workers involved in bread production spend most of their time in the production area and, occasionally-depending upon production rate-when they need to produce new dough, they go to the raw material warehouse where they only spend a few minutes. The production workers normally do not spend time in the store as this workplace has dedicated workers that remain in the store.

The sampling sites and collection periods (depending upon the equipment and assay applied) for each bakery were determined based upon the significant amount of time spent by workers in those places during their occupational activity and the tasks developed in each workplace. In these workstations, environmental samples including air, surfaces, settled dust and electrostatic dust collector (EDC) were obtained for the assessment of fungal burden (fungi and mycotoxins) and sampling performed during a normal working day (Table 1). 


\subsection{Sampling Approaches Characterization}

Air samples of $100 \mathrm{~L}$ were collected through an impaction method with a flow rate of $140 \mathrm{~L} / \mathrm{min}$ (Millipore air Tester, Millipore, Billerica, MA, USA) onto each plate according to manufacturer's instructions. In this case, air samples consisted mainly of 53 indoor samples and one outdoor sample collected in each bakery, which was to be used as a reference. All indoor samples were collected from workplaces occupied per one or two workers. Two different culture media were used in order to enhance the selectivity for fungal population growth: malt extract agar (MEA) supplemented with chloramphenicol (0.05\%) and dichloran glycerol (DG18) agar-based media (Figure 1).

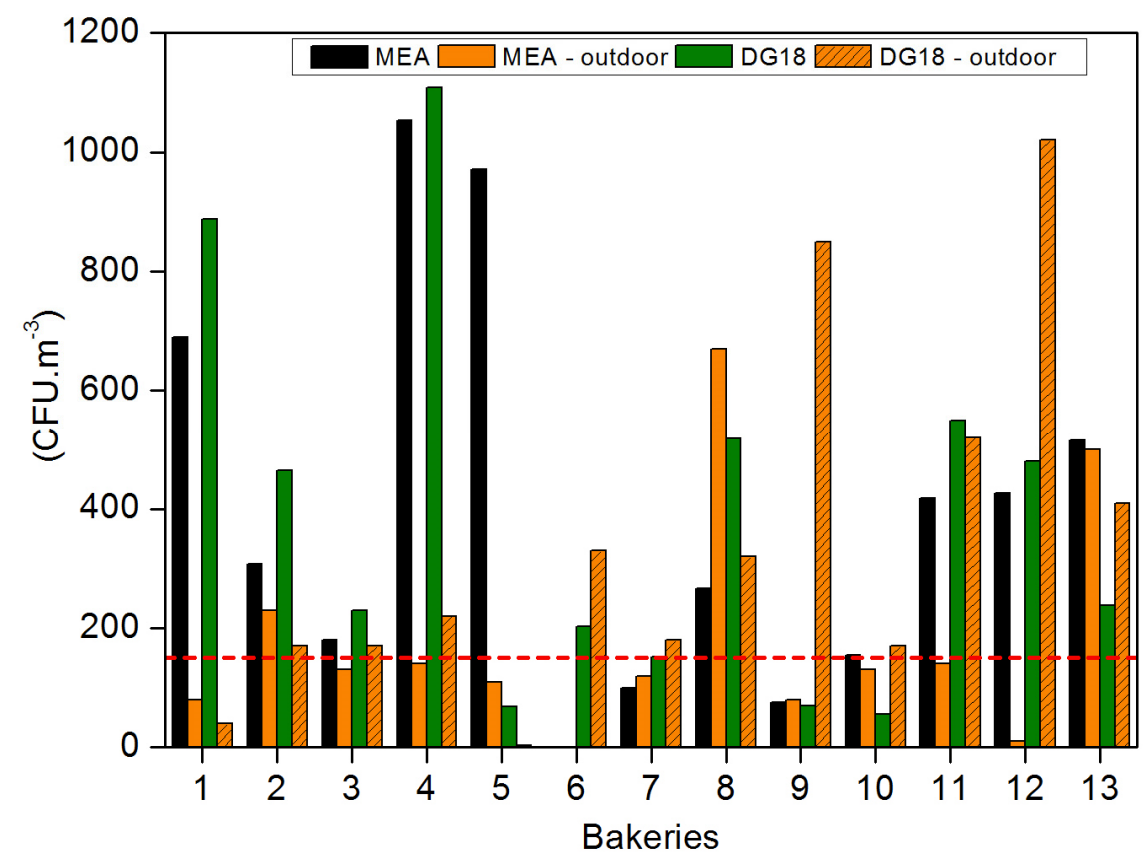

Figure 1. Air fungal load distribution in the 13 assessed bakeries. The dashed line represents the reference limits suggested by the World Health Organization (WHO).

Air samples of $600 \mathrm{~L}$ were collected additionally using the impinger method. Samples were collected onto $10-\mathrm{mL}$ sterile phosphate-buffered saline (PBS) with $0.05 \%$ Triton X-100, as reported previously [10].

For surface samples, the floors (considered as the most critical surface) of the same indoor locations (production, warehouse and store) were swabbed using a 10 by $10 \mathrm{~cm}$ square [10]. Settled dust and EDC sampling approaches were collected and extracted following the procedures previously described [23].

\subsection{Fungal Contamination Characterization}

All collected samples (air samples by impaction, surfaces samples, settled dust and EDC) were incubated at $25 \pm 2{ }^{\circ} \mathrm{C}$ for 5-7 days (fungi). Fungal densities (colony forming units (CFU) per $\mathrm{m}^{3}$, $\mathrm{m}^{2}$ or g) were calculated on both MEA and DG18 media, followed by fungal identification achieved through macro and microscopic characteristics [25].

When colony overgrowth was observed due to fungi with fast growing rates (Mucorales group; Chrysonilia sitophila and Trichoderma spp.), making it impossible to count colonies, a quantitative cut off was applied of 500 isolates (CFU) as in previous published studies [10,26].

\subsection{Molecular Detection of Specific Aspergillus Sections}

Molecular identification of the different fungal species/strains was achieved by Real Time PCR (qPCR) using the Via 7 Real-time PCR System (Applied Biosystems) on air samples collected by the 
impinger method, surface swabs, settled dust and EDC $(n=27)$. Reactions and procedures were the same previously published [10] (Table 2).

Table 2. Sequence of primers and TaqMan probes used for Real Time PCR.

\begin{tabular}{|c|c|c|c|}
\hline \multicolumn{2}{|c|}{ Aspergillus Sections Targeted } & \multirow{4}{*}{$\begin{array}{l}\text { Sequences } \\
\text { 5'-GTCCAAGCAACAGGCCAAGT-3' } \\
\text { 5'-TCGTGCATGTTGGTGATGGT-3' } \\
\text { 5'-TGTCTTGATCGGCGCCCG-3' }\end{array}$} & \multirow{4}{*}{$\begin{array}{l}\text { Reference } \\
{[27]}\end{array}$} \\
\hline \multirow{3}{*}{$\begin{array}{l}\text { Flavi } \\
\text { (Toxigenic Strains) }\end{array}$} & Forward Primer & & \\
\hline & Reverse Primer & & \\
\hline & Probe & & \\
\hline \multirow{3}{*}{ Fumigati } & Forward Primer & 5'-CGCGTCCGGTCCTCG-3' & \\
\hline & Reverse Primer & 5'-TTAGAAAAATAAAGTTGGGTGTCGG-3' & [28] \\
\hline & Probe & 5'-TGTCACCTGCTCTGTAGGCCCG-3' & \\
\hline \multirow{3}{*}{ Circumdati } & Forward Primer & 5'-CGGGTCTAATGCAGCTCCAA-3' & \\
\hline & Reverse Primer & 5'-CGGGCACCAATCCTTTCA-3' & [26] \\
\hline & Probe & 5'-CGTCAATAAGCGCTTTT-3' & \\
\hline \multirow[t]{3}{*}{ Versicolores } & Forward Primer & 5'-CGGCGGGGAGCCCT-3' & [29] \\
\hline & Reverse Primer & 5'-CCATTGTTGAAAGTTTTGACTGATcTTA-3' & \\
\hline & Probe & 5'-AGACTGCATCACTCTCAGGCATGAAGTTCAG-3' & \\
\hline
\end{tabular}

\subsection{Mycotoxins Analyses}

Fifty-three air and 11 settled dust samples were screened for mycotoxins presence. Air samples $(100 \mu \mathrm{L})$ were directly diluted 1:7 $(v / v)$ with a 1:1 mixture of extraction solvent (acetonitrile (ACN): water $\left(\mathrm{H}_{2} \mathrm{O}\right)$ : acetic acid $\left.(\mathrm{AcOH})(79: 20: 1)\right)$ and water. Settled dust samples $(0.25 \mathrm{~g})$ were extracted with $1 \mathrm{~mL} \mathrm{ACN}: \mathrm{H}_{2} \mathrm{O}$ : AcOH (79:20:1) for $60 \mathrm{~min}$. Raw extracts were diluted with the same amount of water, mixed and filtered for mycotoxins detection. Detection of mycotoxins was carried out using high performance liquid chromatograph (HPLC) Nexera (Shimadzu, Tokyo, Japan) with a mass spectrometry detector API 4000 (Sciex, Foster City, CA, USA). Mycotoxins were separated on a chromatographic column Gemini NXC18 $(150 \times 4.6 \mathrm{~mm}, 3 \mu \mathrm{m})$ (Phenomenex, Torrance, CA, USA); mobile phase (A: water $+5 \mathrm{mM}$ ammonium acetate $+1 \%$ acetic acid, $\mathrm{B}$ : methanol $+5 \mathrm{mM}$ ammonium acetate $+1 \%$ acetic acid) mobile phase flow rate: $0.75 \mathrm{~mL} / \mathrm{min}$, injection volume: $7 \mu \mathrm{L}$.

Several mycotoxins were considered in the assessment performed, namely: patulin, nivalenol, deoxynivalenol-3-glucoside, deoxynivalenol, fusarenon- $X, \alpha$-zearalanol, $\beta$-zearalanol, $\beta$-zearalenol, $\alpha$-zearalenol, zearalanone, zearalenone, T2 tetraol, deepoxydeoxynivalenol, neosolaniol, 15-acetyldeoxynivalenol, 3-acetyldeoxynivalenol, monoacetoxyscirpenol, diacetoxyscirpenol, aflatoxin M1, aflatoxin B1, aflatoxin B2, aflatoxin G1, aflatoxin G2, fumonisin B1, fumonisin B2, fumonisin B3, T2 triol, roquefortine C, griseofulvin, T2 toxin, HT2 toxin, ochratoxin A, ochratoxin B, mycophenolic acid, mevinolin. Different Limits of Detection (LOD) and Quantification (LOQ) were obtained for each mycotoxin (Table 3).

\subsection{Statistical Analysis}

Data were analyzed using SPSS statistical software for Windows. The results were considered significant at the level of 5\%. To test the normality of data the Shapiro-Wilk test was used. Regarding sample characterization frequency analysis (n; \%) was performed for qualitative data and the calculation of the minimum and maximum for quantitative data was applied. The Kruskal-Wallis test was employed to compare the concentration of fungi (in air, surface and EDC) between bakeries (from 1 to 13), since the normality assumption was not verified. When statistically significant differences were detected, the Kruskal-Wallis multiple comparison test was used. The Spearman correlation coefficient was utilized to study the relationship between MEA and DG18 fungi concentration in different environmental matrices (air, surfaces and EDC), since the normality assumption was not verified. 
Table 3. Limits of detection (LOD) and Quantification (LOQ) for mycotoxins analysed by LC-MS/MS.

\begin{tabular}{|c|c|c|}
\hline Mycotoxins & $\begin{array}{c}\text { Limit of Detection LOD } \\
\text { (ng/g) }\end{array}$ & $\begin{array}{c}\text { Limit of Quantification (LOQ) } \\
\text { (ng/g) }\end{array}$ \\
\hline Patulin & 1.1 & 3.6 \\
\hline Nivalenol & 4.5 & 14.9 \\
\hline Deoxynivalenol-3-glucoside & 5.4 & 17.8 \\
\hline Deoxynivalenol & 2.7 & 8.9 \\
\hline Fusarenon- $X$ & 4.8 & 15.8 \\
\hline Deepoxy-deoxynivalenol & 4.2 & 13.9 \\
\hline$\alpha$-Zearalanol & 2.0 & 6.6 \\
\hline$\beta$-Zearalanol & 0.9 & 3.0 \\
\hline$\beta$-Zearalenol & 1.4 & 4.6 \\
\hline$\alpha$-Zearalenol & 1.0 & 3.3 \\
\hline Zearalanone & 0.5 & 1.7 \\
\hline Zearalenone & 0.2 & 0.7 \\
\hline T2 Tetraol & 5.4 & 17.8 \\
\hline Deepoxydeoxynivalenol & 0.4 & 1.3 \\
\hline Neosolaniol & 0.1 & 0.3 \\
\hline 15-Acetyldeoxynivalenol & 0.8 & 2.6 \\
\hline 3-Acetyldeoxynivalenol & 0.8 & 2.6 \\
\hline Monoacetoxyscirpenol & 0.1 & 0.3 \\
\hline Diacetoxyscirpenol & 0.3 & 1.0 \\
\hline Aflatoxin M1 & 0.1 & 0.3 \\
\hline Aflatoxin B1 & 0.1 & 0.3 \\
\hline Aflatoxin B2 & 0.1 & 0.3 \\
\hline Aflatoxin G1 & 0.1 & 0.3 \\
\hline Aflatoxin G2 & 0.1 & 0.3 \\
\hline Fumonisin B1 & 0.5 & 1.7 \\
\hline Fumonisin B2 & 0.4 & 1.3 \\
\hline Fumonisin B3 & 0.5 & 1.7 \\
\hline T2 Triol & 0.3 & 1.0 \\
\hline Roquefortine C & 0.2 & 0.7 \\
\hline Griseofulvin & 0.1 & 0.3 \\
\hline $\mathrm{T} 2$ & 0.1 & 0.3 \\
\hline HT2 & 0.3 & 1.0 \\
\hline Ochratoxin A & 0.1 & 0.3 \\
\hline Ochratoxin B & 0.1 & 0.3 \\
\hline Mycophenolic acid & 0.2 & 0.7 \\
\hline Mevinolin & 0.1 & 0.3 \\
\hline
\end{tabular}

\section{Results}

\subsection{Fungal Characterization}

Fungal load in indoor air ranged from 0 to $2590 \mathrm{CFU} \cdot \mathrm{m}^{-3}$ using MEA, with Bakery 4 presenting the highest median value $\left(1053 \mathrm{CFU} \cdot \mathrm{m}^{-3}\right)$, followed by Bakeries 5, 1, 13 and 12 with mean values of $971,690,515$ and $427 \mathrm{CFU} \cdot \mathrm{m}^{-3}$, respectively. Noteworthy, $65.3 \%$ (32 out of 49 ) of the sampling sites showed higher fungal load than the limits imposed by the World Health Organization (WHO) (maximum value of $150 \mathrm{CFU} \cdot \mathrm{m}^{-3}$ ) [30] in 10 bakeries the indoor air load mean was higher than the outdoor fungal load (Figure 1) and 30 out of the 49 (61.2\%) air samples collected presented higher fungal load when compared to the outdoor sampling.

Similar results were found obtained in DG18, with fungal load ranging from 0 to $2620 \mathrm{CFU} \cdot \mathrm{m}^{-3}$ and with Bakery 4 presenting the highest median value $\left(1108 \mathrm{CFU} \cdot \mathrm{m}^{-3}\right)$, followed by Bakeries 1,11 , 8 and 12 , with mean values of $887,550,518$ and $480 \mathrm{CFU} \cdot \mathrm{m}^{-3}$, respectively. DG18 revealed that $62.3 \%$ of the sampling sites with fungal load exceeded the WHO limit; the indoor air load mean in eight bakeries was higher than the outdoor fungal load (Figure 1); and $47.2 \%$ of the air samples presented a higher indoor fungal load when compared to the outdoor sampling. 
Eighteen different fungal species/sections were found in air samples using MEA and 21 species/sections on DG18. Cladosporium spp. was the most prevalent in indoor air samples in both media (29.7\% MEA; 48.7\% DG18), followed by Penicillium spp. (22.3\% MEA; 30.5\% DG18) (Table 4). In addition to these species, Alternaria spp., Aureobasidium spp., Aspergillus sections (Candidi, Circumdati and Nigri), Chrysonilia sp., Chrysosporium spp., Fusarium graminearum, Geotrichum spp., Mucorales order (Mucor and Rhizopus genera), Paecilomyces spp., Trichoderma spp. Ulocladium spp. and Verticillium spp. were isolated as well utilizing MEA. Regarding DG18, in addition to the most prevalent species already mentioned, Aspergillus sections (Aspergilli, Fumigati and Versicolores), Syncephalastrum racemosum (Mucorales order) and Trycothecium roseum were identified.

Table 4. Fungal distribution on the collected environmental samples after inoculation onto MEA and DG18 media.

\begin{tabular}{|c|c|c|c|}
\hline \multicolumn{2}{|c|}{ MEA } & \multicolumn{2}{|c|}{ DG18 } \\
\hline Air & $\left(\mathrm{CFU} \cdot \mathrm{m}^{-3}\right)(\% ; \mathrm{n})$ & Air & $\left(\mathrm{CFU} \cdot \mathrm{m}^{-3}\right)(\% ; \mathrm{n})$ \\
\hline Acremonium sp. & $(17.0 ; 3960)$ & Acremonium sp. & $(2.8 ; 670)$ \\
\hline Chrysonilia sitophila & $(17.2 ; 4000)$ & Chrysonilia sitophila & $(10.3 ; 2500)$ \\
\hline Cladosporium sp. & $(29.7 ; 6920)$ & Cladosporium sp. & $(48.7 ; 11860)$ \\
\hline Mucorales order & $(2.2 ; 520)$ & Geotrichum sp. & $(2.5 ; 620)$ \\
\hline Penicillium sp. & $(22.3 ; 5190)$ & Penicillium sp. & $(30.5 ; 7420)$ \\
\hline Others & $(11.7 ; 2730)$ & Others & $(5.2 ; 1270)$ \\
\hline Surfaces & $\left(\mathrm{CFU} \cdot \mathrm{m}^{-2}\right)(\% ; n)$ & Surfaces & $\left(\mathrm{CFU} \cdot \mathrm{m}^{-2}\right)(\% ; n)$ \\
\hline \multirow{6}{*}{$\begin{array}{l}\text { Acremonium sp. } \\
\text { Chrysonilia sitophila } \\
\text { Cladosporium sp. } \\
\text { Penicillium sp. } \\
\text { Others }\end{array}$} & \multirow{6}{*}{$\begin{array}{c}(7.7 ; 2040000) \\
(75.8 ; 20000000) \\
(10.7 ; 2820000) \\
(4.0 ; 1050000) \\
(1.8 ; 480500)\end{array}$} & Acremonium sp. & $(4.7 ; 1370000)$ \\
\hline & & Chrysonilia sitophila & (51.6;15020000) \\
\hline & & Cladosporium sp. & $(10.5 ; 3070000)$ \\
\hline & & Mucorales order & $(17.5 ; 5110000)$ \\
\hline & & Penicillium sp. & $(12 ; 3500000)$ \\
\hline & & Others & $(3.6 ; 1060000)$ \\
\hline EDC & $\left(\mathrm{CFU} \cdot \mathrm{m}^{-2}\right)(\% ; n)$ & EDC & $\left(\mathrm{CFU} \cdot \mathrm{m}^{-2}\right)(\% ; \mathrm{n})$ \\
\hline \multirow{5}{*}{$\begin{array}{l}\text { Chrysonilia sitophila } \\
\text { Cladosporium sp. } \\
\text { Penicillium sp. } \\
\text { Others }\end{array}$} & \multirow{5}{*}{$\begin{array}{c}(91.9 ; 124403) \\
(2.5 ; 3434) \\
(5.0 ; 6718) \\
(0.6 ; 746)\end{array}$} & Aspergillus sp. & $(2.3 ; 597)$ \\
\hline & & Chrysosporium sp. & $(3.1 ; 796)$ \\
\hline & & Cladosporium sp. & $(55.8 ; 14480)$ \\
\hline & & Penicillium sp. & $(38.3 ; 9952)$ \\
\hline & & Others & $(0.5 ; 149)$ \\
\hline
\end{tabular}

Fungal load in surface swabs samples and EDC was distributed as follows: 0 to $51 \times 10^{5} \mathrm{CFU} \cdot \mathrm{m}^{-2}$ (MEA) and 0 to $101.3 \times 10^{5} \mathrm{CFU} \cdot \mathrm{m}^{-2}$ (DG18) and 0 to $3135 \mathrm{CFU} \cdot \mathrm{m}^{-2}$ (MEA) and 0 to $4180 \mathrm{CFU} \cdot \mathrm{m}^{-2}$ (DG18), respectively. Ten different fungal species/sections were found in surface swab samples on MEA and 13 on DG18 with C sitophila the most prevalent (75.8\% MEA; 51.6\% DG18). In addition Aspergillus sections (Candidi and Versicolores), Chrysosporium spp., Phoma spp., Rhizopus spp. (Mucorales order) and Scopulariopsis brevicaulis were identified with MEA, while Aspergillus sections (Aspergilli, Candidi, Circumdati, Nigri and Versicolores), Chrysosporium spp., Geotrichum spp., Mucorales order (Mucor spp. and Rhizopus spp.) and Phoma spp. were found with DG18.

With the use of EDC, it was possible to identify 11 different species/sections with MEA and 9 with on DG18. C. sitophila (91.9\%) was the species most detected in EDC using MEA, whereas Cladosporium spp. (55.8\%) and Penicillium spp. (38.3\%) were the most noted with DG18 (Table 4). In addition to the most prevalent species, it was possible to isolate Aspergillus sections (Aspergilli, Candidi, Circumdati, Flavi and Fumigati,), F. culmorum, Paecilomyces spp. and Syncephalastrum racemosum (Mucorales order) on MEA plates and Acremonium spp. and Paecilomyces spp. on DG18 plates.

Settled dust did not show any fungal growth.

Aspergillus genera was detected in air samples using MEA and DG18 $(0.3 \%$ and $1.3 \%$, respectively). Aspergillus section Candidi was the most prevalent (62.5\%) with MEA followed by Nigri (25\%), 
whereas Aspergillus sections Candidi and Circumdati (35.5\%) were more prevalent on DG18 followed by Aspergilli (22.6\%).

Aspergillus genera was found with MEA and DG18 (1.6\% and 3\%, respectively) on surface swabs samples. Aspergillus section Candidi and Aspergillus section Versicolores were the most prevalent species using MEA (50\% each), whereas Aspergillus section Versicolores (88.5\%) was more prevalent with DG18 followed by Aspergillus section Candidi (5.7\%).

Regarding EDC, Aspergillus genera was observed with MEA and DG18 (0.4\% and 2.3\%, respectively). Aspergillus section Candidi was the most prevalent using MEA (50\%) followed by Aspergillus section Circumdati (25\%), whereas Aspergillus sections Fumigati (50\%) was more prevalent with DG18 followed by Aspergillus sections Candidi (33.3\%) (Table 5).

Table 5. Aspergillus sections' distribution in the collected samples.

\begin{tabular}{|c|c|c|c|}
\hline \multicolumn{2}{|c|}{ MEA } & \multicolumn{2}{|c|}{ DG18 } \\
\hline Air & $\left(\mathrm{CFU} \cdot \mathrm{m}^{-3}\right)(\% ; \mathrm{n})$ & Air & $\left(\mathrm{CFU} \cdot \mathrm{m}^{-3}\right)(\% ; n)$ \\
\hline \multirow{6}{*}{$\begin{array}{c}\text { Candidi } \\
\text { Circumdati } \\
\text { Nigri }\end{array}$} & \multirow{6}{*}{$\begin{array}{c}(62.5 ; 50) \\
(12.5 ; 10) \\
(25 ; 20)\end{array}$} & Aspergilli & $(22.6 ; 50)$ \\
\hline & & Candidi & $(35.5 ; 110)$ \\
\hline & & Circumdati & $(35.5 ; 110)$ \\
\hline & & Fumigati & $(3.2 ; 10)$ \\
\hline & & Nigri & $(3.2 ; 10)$ \\
\hline & & Versicolores & $(3.2 ; 10)$ \\
\hline Surfaces swabs & $\left(\mathrm{CFU} \cdot \mathrm{m}^{-2}\right)(\% ; n)$ & Surfaces swabs & $\left(\mathrm{CFU} \cdot \mathrm{m}^{-2}\right)(\% ; n)$ \\
\hline \multirow{5}{*}{$\begin{array}{c}\text { Candidi } \\
\text { Versicolores }\end{array}$} & \multirow{5}{*}{$\begin{array}{l}(50 ; 210000) \\
(50 ; 210000)\end{array}$} & Aspergilli & $(1.1 ; 10000)$ \\
\hline & & Candidi & $(5.7 ; 50000)$ \\
\hline & & Circumdati & $(2.3 ; 20000)$ \\
\hline & & Nigri & $(2.3 ; 20000)$ \\
\hline & & Versicolores & $(88.5 ; 870000)$ \\
\hline EDC & $\left(\mathrm{CFU} \cdot \mathrm{m}^{-2}\right)(\% ; n)$ & EDC & $\left(\mathrm{CFU} \cdot \mathrm{m}^{-2}\right)(\% ; \mathrm{n})$ \\
\hline Aspergilli & $(8.3 ; 50)$ & Aspergilli & $(8.3 ; 50)$ \\
\hline Candidi & $(50 ; 299)$ & Candidi & $(33.3 ; 199)$ \\
\hline Circumdati & $(25 ; 149)$ & Fumigati & $(50 ; 299)$ \\
\hline Flavi & $(8.3 ; 50)$ & Versicolores & $(8.3 ; 50)$ \\
\hline Fumigati & $(8.3 ; 50)$ & & \\
\hline
\end{tabular}

Molecular detection—by real time PCR—of the target Aspergillus sections Flavi and Circumdati was negative for all environmental matrices analyzed. However, it was possible to detect Aspergillus section Fumigati in $22.4 \%$ on air samples by impinger samples, $27.8 \%$ on surface swabs and in $7.4 \%$ on EDC samples and Aspergillus section Versicolores on one air sample. In any of the samples detected, the target fungal sections/species had growth observed for the same sections/species.

\subsection{Mycotoxins Contamination}

None of the 36 mycotoxins were detected in air samples. Regarding settled dust, all samples showed contamination with 6 to 8 mycotoxins in each sample. The mycotoxins detected are presented in Table 6. DON was clearly the mycotoxin measured in higher amounts as all the samples identified quantifiable results (Table 6).

\subsection{Comparison Analyses}

Significant differences of fungal load were detected in air samples and on surface swabs either with MEA or DG18. The multiple comparisons test Kruskal-Wallis which was applied to air samples, showed that the bakeries that differed significantly using MEA were Bakeries 7, 9 and 10 of Bakeries 1 , 4,5 and 13. It was found as well that Bakeries 7,8 and 10 presented the lowest concentrations of fungal 
load (Figure 2). As for DG18, the bakeries that differed significantly were Bakeries 5, 6, 9 and 10 of 1,4, 8 and 11. Bakeries 5, 6, 9 and 10 were the ones with lower concentrations (Figure 2).

Table 6. Mycotoxins contents (>LOD) in settled dust (ng/g).

\begin{tabular}{ccc}
\hline Mycotoxins & $\begin{array}{c}\text { Number of Samples with } \\
\text { Detectable Values }\end{array}$ & Concentration Range \\
\hline DON & $12(100 \%)$ & $15.95-211$ \\
D3G & $9(75 \%)$ & $<$ LOQ-25.77 \\
ZEA & $12(100 \%)$ & $<$ LOQ-1.60 \\
15-ADON & $3(25 \%)$ & $5.01-5.22$ \\
MAS & $6(50 \%)$ & $0.40-1.6$ \\
DAS & $1(8.3 \%)$ & $<$ LOQ \\
FB1 & $3(25 \%)$ & $5.23-7.36$ \\
FB2 & $4(33.3 \%)$ & $3.73-5.49$ \\
GRIS & $1(8.3 \%)$ & 5.90 \\
HT2 & $2(16.6 \%)$ & $0.99-1.93$ \\
OTA & $10(83.3 \%)$ & $<$ LOQ- 0.64 \\
OTB & $1(8.3 \%)$ & 0.54 \\
MPA & $7(58.3 \%)$ & $<$ LOQ-3.04 \\
\hline
\end{tabular}

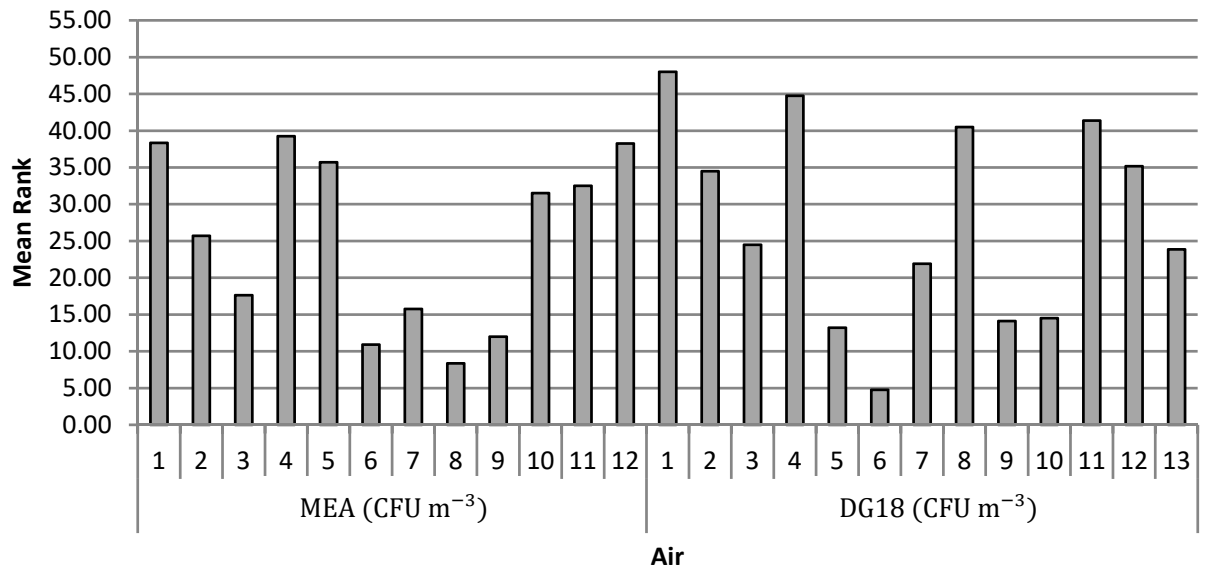

Figure 2. Mean ranks of fungal load $\left(\mathrm{CFU} \mathrm{m}{ }^{-3}\right)$ on MEA and DG18 on the air in each bakery.

Regarding the surfaces, the load on MEA from Bakeries 4, 2, 6, 7 and 8 differed significantly from Bakeries 10 and 5 with the latter having the highest fungal load. As for the surfaces load using DG18, Bakeries 2, 3, 6, 7 and 8 differed from Bakeries 13, 12 and 10 indicating that Bakeries 2, 3, 6, 7 and 8 were the ones with the lowest fungal load (Figure 3).

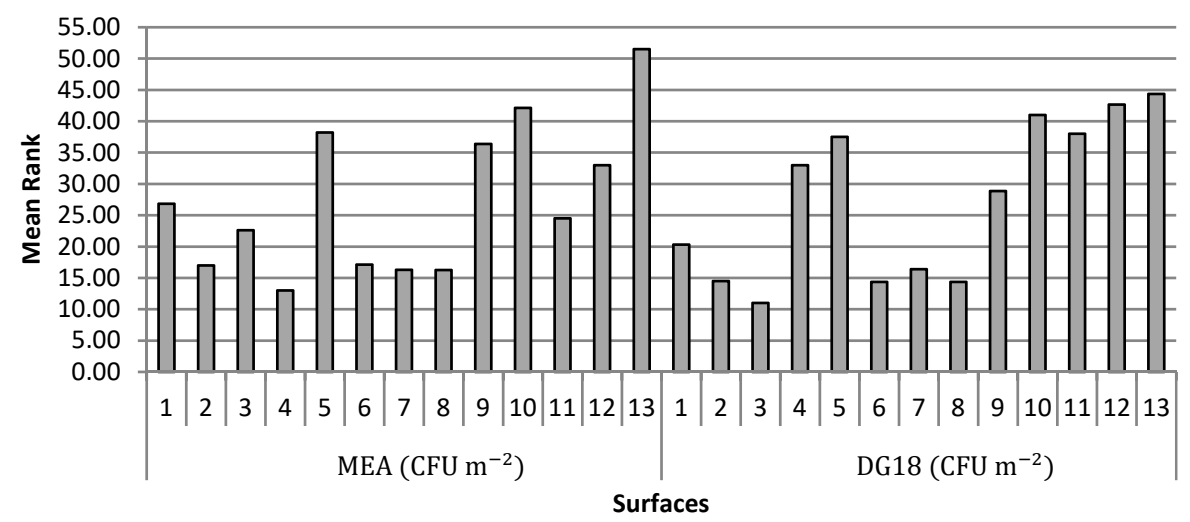

Figure 3. Mean ranks of fungal load $\left(\mathrm{CFU} \mathrm{m}{ }^{-2}\right)$ on MEA and DG18 on the surface swabs in each bakery. 
The fungal load with MEA from EDC in Bakeries 2, 3, 4 and 6 differed significantly from Bakeries 5 and 10, which had a higher load (Figure 4).

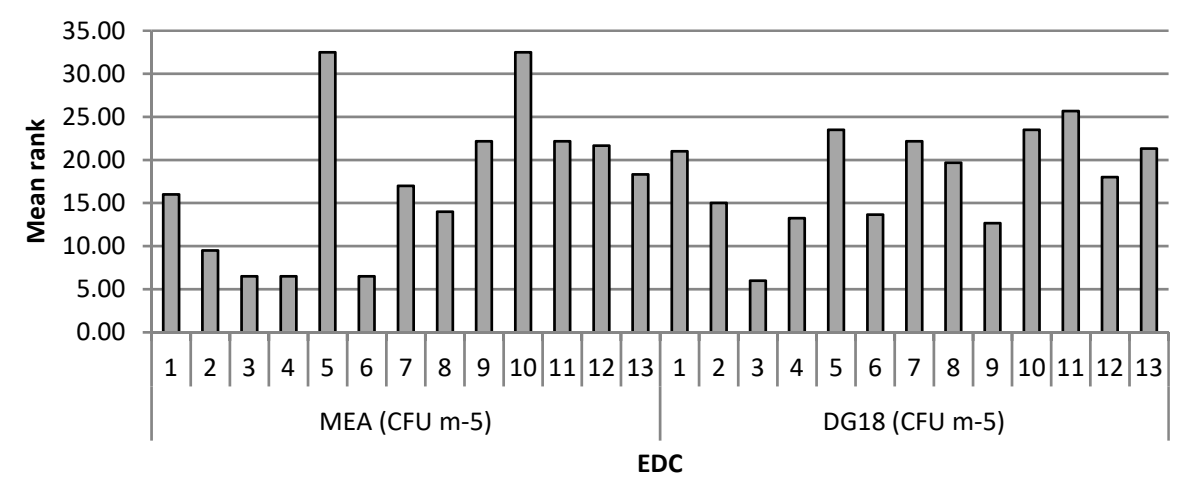

Figure 4. Mean ranks of fungal load $\left(\mathrm{CFU} \mathrm{m} \mathrm{m}^{-2}\right)$ on MEA and DG18 on EDC in each bakery.

Significant positive and weak intensity correlations were detected between: (a) air fungal load with MEA and surface swab load with DG18; (b) the surface swab load with MEA with surface swab load on DG18 the EDC fungal load on MEA surface swab load on DG18 $\left(\mathrm{r}_{\mathrm{S}}=0.584, p=0.000\right)$; (c) the surface swab load on DG18 with the EDC fungal load on MEA; (d) EDC fungal load on MEA with EDC fungal load on DG18. These results indicate that the higher load of some sampling methods in specific culture media is related to the higher load of others (sampling methods/specific culture media).

A significant negative correlation with weak intensity, was detected between air fungal load on DG18 and surface fungal load on MEA. Data indicate that higher air fungal load on DG18 are related to lower surface load on MEA.

\section{Discussion}

In this study, different sampling methods (active and passive), varying devices (impaction and impinger for active and surface swabs, settled dust and EDC for passive methods) and differing assays (culture-based with two different media and molecular tools) were applied. This multi-approach technique has advantages for the identification of Aspergillus sections Flavi and Fumigati on EDC by culture based-methods and detection of Aspergillus section Fumigati on air, surface swabs and EDC and Aspergillus section Versicolores on air by molecular tools that were not noted by culture-based methods. Indeed, complementarity of culture-based methods and molecular tools for occupational exposure assessments is well reported on literature overcoming the drawbacks of each other $[22,23,26]$. Further, different species were found in each media used (MEA and DG18), with an increased Aspergillus species identification on DG18, corroborating the findings already reported in different occupational environments [10]. These results reinforce the use of DG18 media, in addition to MEA as the default approach for microbiological analysis-even if the counts in both media correlated in some of the environmental matrices. Furthermore, DG18 was already reported as inhibitor of the spreading of Mucorales group, such as Mucor spp. and Rhizopus spp. and restrains the colony size of other fast-growing genera [31], allowing others, like Aspergillus genera, to grow.

In addition, it was possible to detect mycotoxins on settled dust, whereas this was not the case on air sampling (active methods). In fact, assessing mycotoxins through passive methods (allowing the determination of the contamination levels of a greater period of time), such as settled dust or other environmental samples that collect contamination instead of load appears to be the trend for the mycotoxins contamination assessment in occupational environments [32-34].

Impinger air samples were exclusively used for fungal assessment by molecular tools as previous results [23] indicating that the impaction method was the best active sampling approach for the occupational exposure assessment of the viable bioburden in this specific occupational environment [23]. Of relevance, is the fact that $76.9 \%$ (10 out of 13) of the assessed bakeries exceeded the WHO guidelines 
in at least one of the applied media and 30 air samples on MEA, and presented a higher fungal load than outdoors, potentially indicating indoor sources of fungal contamination, such as workers and their activities which contribute to indoor airborne microbial load [35] as well as raw materials entering the facilities [6,8]. Among the 13 bakeries assessed, fungal species with toxigenic potential [36] were identified in all environmental matrices where fungal growth occur, including Penicillium spp., Fusarium spp. and Aspergillus sections.

However, although it was not possible to observe or detect fungal growth in settled dust samples, several mycotoxins were present. Mycotoxins persist in an occupational environment even in fungi absence as they resist to adverse abiotic factors such as temperature $[37,38]$ and this is the reason why lack of fungal growth cannot be used as a surrogate for non-detectable mycotoxins' contamination [39]. Indeed, mycotoxins are commonly present in airborne dust [40,41] and in fungal spores or fragments of microbial growth, and both can act as mycotoxin carriers to the workers respiratory system, since mycotoxins are not volatile [42]. This is an important characteristic because-as already mentioned in this occupational setting-exposure to organic dust is commonly observed $[43,44]$ and can enhance exposure to mycotoxins by inhalation. Thus, the most common scenario, found in other occupational settings as well, is the co-exposure to more than one risk factor-fungi and metabolites (mycotoxins) [10,26]. Overall, this multi-approach on sampling methods (active and passive) and lab assays (culture based-methods and molecular tools) enriched data findings, enabling a more detailed risk [10,22], and the identification of potential fungal and mycotoxin contamination sources (flour and other raw materials on settled dust composition).

Limitations in this study was the potential influence of climacteric conditions on the seasonal distribution of fungal species, such as Alternaria, Aspergillus, Cladosporium and Penicillium, as some bakeries were sampled in the winter season and others during spring season [45]. Whereas the sample is constituted by only two bakery companies, the total comprised 13 bakeries exemplify a reliable picture of bakery industry in Portugal concerning workload, workplace layout, environmental parameters, production processes, and final food commodities produced.

Considering the obtained results, further studies are needed to improve our understanding of the occupational environment of the bakeries. A previous study developed in a similar occupational setting — the milling industry [46]—using biomonitoring tools, did not demonstrate additional risk for workers related to occupational exposure to mycotoxins. However, different tasks, workplace conditions, production processes and even different outdoor climatic conditions might affect individuals regarding mycotoxins exposure. Indeed, a study developed in a fresh bread dough company located in Portugal showed that workplace exposure to specific mycotoxins added significantly to the exposure of mycotoxins occurring by ingestion [17], particularly in the case of deoxynivalenol. Moreover, the study demonstrated that both workers and controls are exposed to several mycotoxins simultaneously. Such exposure constitutes a large potential of associated health effects due to the synergistic and/or additive toxicities, which are not still completely understood scientifically [47]. Therefore, we should consider that the risk of a mixture typically exceeds the risk of each individual mixture component and second, even when it is guaranteed that all compounds of a mixture are present at concentrations that are considered safe from a health or regulatory perspective, the resulting mixture can still cause health effects [48]. More research work should be developed to elucidate the possible interactions among mycotoxins and to support the definition of new health-based guidance values for grouped mycotoxins and/or co-occurring mycotoxins in order to prevent human disease [47].

Considering the results obtained in this study, it is possible to understand that the fungal burden is an important component of the bakeries environment and, as mentioned before, can have a role in "baker's asthma" as well. Future work should be developed to assess the impact on workers' health of the simultaneous exposure to all the risk factors in presence (e.g., cereals' flours, fungi and their metabolites) and to try to understand whether the mixture can play a role in "baker's asthma" disease. 


\section{Conclusions}

The multi-approach analysis based on the use of different sampling methods (active and passive), different sampling devices (impaction and impinger for active and surface swabs, settled dust and EDC for passive methods), and different assays allowed for a wider spectrum of the fungal burden in the assessed bakeries to be obtained. Thus, industrial hygienists and exposure assessors should rely on different sampling methods (active and passive) and different assays (culture based and molecular methods) to obtain an accurate risk characterization regarding fungal burden. The results obtained regarding fungal load and contamination emphasizes the increased exposure to this occupational risk, besides other relevant allergens commonly present in the environment, and the need for further studies to improve understanding of this setting and develop surveillance and intervention programs aimed at the improvement and protection of the respiratory health of bakery workers. The information regarding settled dust contamination by several mycotoxins was useful for the awareness for the presence of this occupational risk and to ponder the raw material (e.g., flour) as an indoor contamination source.

Author Contributions: Conceptualization, C.V., and S.V.; Methodology, C.V. and S.V.; Validation, C.V. and S.V.; Formal Analysis, E.C.; Investigation, C.V., T.F., L.A.C., A.Q.-G., M.T., R.K. and S.V.; Resources, C.V. and S.V.; Data Curation, C.V., T.F., L.A.C., E.C., A.Q.-G., M.T., R.K. and S.V.; Writing-Original Draft Preparation, C.V.; Writing-Review \& Editing, C.V., T.F., L.A.C., A.Q.-G., M.T., R.K. and S.V.; Visualization, C.V., T.F., L.A.C., E.C., A.Q.-G., M.T., R.K. and S.V.; Supervision, S.V.; Project Administration, S.V.; Funding Acquisition, C.V. and S.V.

Funding: The authors are grateful to the Portuguese authority for working conditions for funding the project "Occupational exposure assessment to particulate matter and fungi and health effects of workers from Portuguese Bakeries||" (005DBB/12) and to Polish Minister of Science and Higher Education, under the program "Regional Initiative of Excellence" in 2019-2022 (Grant No. 008/RID/2018/19). Carla Viegas is thankful to Fundação para Ciência e Tecnologia (FCT) for funding the project EXPOsE, establishing protocols to assess occupational exposure to microbiota in clinical settings (02/SAICT/2016 - Project $\left.n^{\circ} 23222\right)$.

Conflicts of Interest: The authors declare no conflicts of interest.

\section{References}

1. Guiné, R.; Matos, M.; Henriques, C.; Correia, P. Preferences and consumer habits related to bread in the centre of Portugal. Nutr. Food Sci. 2016, 46, 306-320. [CrossRef]

2. Page, E.H.; Dowell, C.H.; Mueller, C.A.; Biagini, R.E. Evaluation of Sensitization and Exposure to Flour Dust, Spices, and Other Ingredients Among Poultry Breading Workers; Technical Report No. 2009-0131-3171; US Department of Health and Human Services Centers for Disease Control and Prevention, National Institute for Occupational Safety and Health: Washington, DC, USA, 2013.

3. Brisman, J. Baker's asthma. Occup. Environ. Med. 2002, 59, 498-502. [CrossRef] [PubMed]

4. Cotton, D.J.; Dosman, J.A. Grain dust and health III. Environmental factors. Anal. Int. Med. 1978, 89, 420-421. [CrossRef] [PubMed]

5. Karpinski, E.A. Exposure to inhalable flour dust in Canadian flour mills. Appl. Occup. Environ. Hyg. 2003, 18, 1022-1030. [CrossRef] [PubMed]

6. Cullinan, P.; Cook, A.; Nieuwenhuijsen, M.J. Allergen and dust exposure as determinations of work-related symptoms and sensitization in a choort of flour-exposure workers: A case control analysis. Ann. Occup. Hyg. 2001, 45, 97-103. [CrossRef]

7. Milanowski, J.; Góra, A.; Skórska, C.; Mackiewicz, B.; Krysinska-Traczyk, E.; Cholewa, G.; Sitkowska, J.; Dutkiewicz, J. The effects of exposure to organic dust on the respiratory system of potato processing workers. Ann. Agric. Environ. Med. 2002, 9, 243-247. [PubMed]

8. Meo, S.A.; Al-Dress, A.M. Lung function among nonsmoking wheat flour mill workers. Int. J. Occup. Med. Environ. Health 2005, 18, 259-264.

9. Viegas, C.; Faria, T.; Monteiro, A.; Aranha, L.C.; Carolino, E.; Gomes, A.Q.; Viegas, S. A novel multi approach protocol for the characterization of occupational exposure to organic dust-Swine production case study. Toxics 2018, 6, 5. [CrossRef]

10. Anukul, N.; Vangnai, K.; Mahakarnchanakul, W. Significance of regulation limits in mycotoxin contamination in Asia and risk management programs at the national level. J. Food Drug Anal. 2013, 21, 227-241. [CrossRef] 
11. Jargot, D.; Melin, S. Characterization and validation of sampling and analytical methods for mycotoxins in workplace air. Environ. Sci. Process. Impacts 2013, 15, 633-644. [CrossRef]

12. Viegas, S.; Veiga, L.; Malta-Vacas, J.; Sabino, R.; Figueiredo, P.; Almeida, A.; Viegas, C.; Carolino, E. Occupational exposure to aflatoxin (AFB (1)) in poultry production. J. Toxicol. Environ. Heal. Part A 2012, 75, 1330-1340. [CrossRef] [PubMed]

13. Viegas, S.; Veiga, L.; Figueiredo, P.; Almeida, A.; Carolino, E.; Sabino, R.; Veríssimo, C.; Viegas, C. Occupational exposure to aflatoxin B1: The case of poultry and swine production. World Mycotoxin J. 2013, 6, 309-315. [CrossRef]

14. Viegas, S.; Veiga, L.; Figueiredo, P.; Almeida, A.; Carolino, E.; Viegas, C. Assessment of workers' exposure to aflatoxin B1 in a Portuguese waste industry. Ann. Occup. Hyg. 2015, 59, 173-181. [CrossRef]

15. Viegas, S.; Viegas, C.; Oppliger, O. Occupational exposure to mycotoxins: Current knowledge and prospects. Ann. Work Expo. Health 2018, 62, 923-941. [CrossRef] [PubMed]

16. Viegas, S.; Assunção, R.; Nunes, C.; Osteresch, B.; Twaruzek, M.; Kosicki, R.; Grajewski, J.; Martins, C.; Alvito, P.; Almeida, A. Exposure assessment to mycotoxins in a Portuguese fresh bread dough company by using a multi-biomarker approach. Toxins 2018, 10, 342. [CrossRef] [PubMed]

17. Viegas, S.; Assunção, R.; Martins, C.; Nunes, C.; Osteresch, B.; Twarużek, M.; Kosicki, R.; Grajewski, J.; Ribeiro, E.; Viegas, C. Occupational exposure to mycotoxins in swine production: Environmental and biological monitoring approaches for exposure assessment. Toxins 2019, 11, 78. [CrossRef] [PubMed]

18. Patouchas, D.; Sampsonas, F.; Papantrinopoulou, D.; Tsoukalas, G.; Karkoulias, K.; Spiropoulos, K. Determinants of specific sensitization in flour allergens in workers in bakeries with use of skin prick tests. Eur. Rev. Med. Pharmacol. Sci. 2009, 13, 407-411. [PubMed]

19. Subbarao, P.; Mandhane, P.J.; Sears, M.R. Asthma: Epidemiology, etiology and risk factors. Cmaj 2009, 181, 181-190. [CrossRef]

20. Meo, S.A. Dose responses of years of exposure on lung function in flour mill workers. J. Occup. Health. 2004, 46, 187-191. [CrossRef]

21. Reponen, T. Sampling for microbial determinations. In Exposure to Microbiological Agents in Indoor and Occupational Environments; Viegas, C., Viegas, S., Quintal Gomes, A., Taubel, M., Sabino, R., Eds.; Springer Nature: New York, NY, USA, 2017.

22. Viegas, C.; Faria, T.; Cebola de Oliveira, A.; Aranha Caetano, L.; Carolino, E.; Quintal-Gomes, A.; Twarużek, M.; Kosicki, R.; Soszczyńska, E.; Viegas, S. A new approach to assess fungal contamination and mycotoxins occupational exposure in forklifts drivers from waste sorting. Mycotoxin Res. 2017, 33, 285-295. [CrossRef]

23. Viegas, C.; Monteiro, A.; Carolino, E.; Viegas, S. Occupational exposure to bioburden in Portuguese bakeries. What should be the sampling approach applied to collect viable microbial load? Arch. Ind. Hyg. Toxicol. 2018, 69, 250-257.

24. Caetano, L.A.; Faria, T.; Batista, A.C.; Viegas, S.; Viegas, C. Assessment of occupational exposure to azole resistant fungi in 10 Portuguese bakeries. Aims Microbiol. 2017, 3, 960-975. [CrossRef] [PubMed]

25. De Hoog, G.S.; Guarro, J.; Gebé, J.; Figueras, M.J. Atlas of Clinical Fungi, 2nd ed.; Centraalbureau voor Schimmelcultures: Utrecht, The Netherlands, 2000.

26. Viegas, C.; Faria, T.; Aranha Caetano, L.; Carolino, E.; Quintal Gomes, A.; Viegas, S. Aspergillus spp. prevalence in different occupational settings. J. Occup. Environ. Hyg. 2017, 14, 771-785. [CrossRef] [PubMed]

27. Mayer, Z.; Bagnara, A.; Färber, P.; Geisen, R. Quantification of the copy number of nor-1, a gene of the aflatoxin biosynthetic pathway by real-time PCR, and its correlation to the cfu of Aspergillus flavus in foods. Int. J. Food Microbiol. 2003, 82, 143-151. [CrossRef]

28. Cruz-Perez, P.; Buttner, M.P.; Stetzenbach, L.D. Detection and quantitation of Aspergillus fumigatus in pure culture using polymerase chain reaction. Mol. Cell. Probes 2001, 15, 81-88. [CrossRef]

29. EPA, United States Environmental Protection Agency. About the National Exposure Research Laboratory (NERL). Available online: http://www.epa.gov/nerlcwww/moldtech.htm (accessed on 19 June 2017).

30. World Health Organization. Indoor Air Quality: Biological Contaminants: Report on a WHO Meeting; WHO Regional Publications European Series, No. 31; WHO: Copenhagen, Denmark, 1988.

31. Bergwall, C.; Stehn, B. Comparison of selective mycological agar media for the isolation and enumeration of xerophilic moulds and osmotolerant yeasts in granulated white sugar. Zuckerindustrie 2002, 127, 259-264. 
32. Mo, X.; Lai, H.; Yang, Y.; Xiao, J.; He, K.; Liu, C.; Chen, J.; Lin, Y. How does airway exposure of aflatoxin B1 affect serum albumin adduct concentrations? Evidence based on epidemiological study and animal experimentation. J. Toxicol. Sci. 2014, 39, 645-653. [CrossRef]

33. Lai, H.; Mo, X.; Yang, Y.; He, K.; Xiao, J.; Liu, C.; Chen, J.; Lin, Y. Association between aflatoxin B1 occupational airway exposure and risk of hepatocellular carcinoma: A case-control study. Tumor Biol. 2014, 35, 9577-9584. [CrossRef]

34. Straumfors, A.; Uhlig, S.; Eriksen, G.S.; Heldal, K.K.; Eduard, W.; Krska, R.; Sulyok, M. Mycotoxins and other fungal metabolites in grain dust from Norwegian grain elevators and compound feed mills. World Mycotoxin J. 2014, 8, 361-373. [CrossRef]

35. Jürgensen, C.W.; Madsen, A.M. Influence of everyday activities and presence of people in common indoor environments on exposure to airborne fungi. AIMS Environ. Sci. 2016, 3, 77-95. [CrossRef]

36. Varga, J.; Baranyi, N.; Chandrasekaran, M.; Vágvölgyi, C.; Kocsubé, S. Mycotoxin producers in the Aspergillus genus: An update. Acta Biologica Szegediensis 2015, 59, 151-167.

37. Alborch, L.; Bragulat, M.R.; Abarca, M.L.; Cabañes, F.J. Effect of water activity, temperature and incubation time on growth and ochratoxin A production by Aspergillus niger and Aspergillus carbonarius on maize kernels. Int. J. Food Microbiol. 2011, 147, 53-57. [CrossRef] [PubMed]

38. Halstensen, A.S. Species-specific Fungal DNA in airborne dust as surrogate for occupational mycotoxin exposure? Int. J. Mol. Sci. 2008, 9, 2543-2558. [CrossRef] [PubMed]

39. Mayer, S. Occupational exposure to mycotoxins and preventive measures. In Environmental Mycology in Public Health; Viegas, C., Pinheiro, C., Sabino, R., Viegas, S., Brandão, J., Veríssimo, C., Eds.; Elsevier: Amsterdam, The Netherlands, 2015; pp. 325-341. [CrossRef]

40. Croft, W.A.; Jarvis, B.B.; Yatawara, C.S. Airborne outbreak of trichothecene toxicosis. Atmos. Environ. 1986, 20, 549-552. [CrossRef]

41. Flannigan, B. Mycotoxins in the air. Int. Biodeterior. 1987, 23, 73-78. [CrossRef]

42. Huttunen, K.; Korkalainen, M. Microbial secondary metabolites and knowledge on inhalation effects. In Exposure to Microbiological Agents in Indoor and Occupational Environments; Viegas, C., Viegas, S., Gomes, A., Täubel, M., Sabino, R., Eds.; Springer International Publishing: Cham, Germany, 2017; pp. 213-234. [CrossRef]

43. Burstyn, I.; Teschke, K.; Kennedy, S. Exposure levels and determinants of inhalable dust exposure in bakeries. Ann. Occup. Hyg. 1997, 41, 609-624. [CrossRef]

44. Roberge, B.; Aubin, S.; Cloutier, Y. Characterization of Dusts in Traditional Bakeries; Technical Report No R-760; Bibliothèque et Archives nationales du Québec: Montreal, QC, Canada, 2012; ISBN 978-2-89631-645-8.

45. De Ana, S.G.; Torres-Rodriguez, J.M.; Alvarado Ramirez, E.; Garcia, S.M.; Belmonte-Soler, J. Seasonal distribution of Alternaria, Aspergillus, Cladosporium and Penicillium species isolated in homes of fungal allergic patients. J. Investig. Allergol. Clin. Immunol. 2006, 16, 357-363. [PubMed]

46. Föllmann, W.; Ali, N.; Blaszkewicz, M.; Degen, G.H. Biomonitoring of mycotoxins in urine: Pilot study in mill workers. J. Toxicol. Environ. Health Part A 2016, 79, 1015-1025. [CrossRef] [PubMed]

47. Assunção, R.; Silva, M.J.; Alvito, P. Challenges in risk assessment of multiple mycotoxins in food. World Mycotoxin J. 2016, 9, 791-811. [CrossRef]

48. KEMI The Swedish Chemicals Agency. An Additional Assessment Factor (MAF)—A Suitable Approach for Improving the Regulatory Risk Assessment of Chemical Mixtures? Swedish Chemicals Agency Print: Arkitektkopia, Stockholm, Sweden, 2015; ISSN 0284-1185.

(C) 2019 by the authors. Licensee MDPI, Basel, Switzerland. This article is an open access article distributed under the terms and conditions of the Creative Commons Attribution (CC BY) license (http://creativecommons.org/licenses/by/4.0/). 